\title{
External morphology of the cycliophoran dwarf male: a comparative study of Symbion pandora and S. americanus
}

\author{
Ricardo Cardoso Neves • Marina Ribeiro da Cunha • \\ Peter Funch · Andreas Wanninger • \\ Reinhardt Møbjerg Kristensen
}

Received: 29 January 2010/Revised: 26 April 2010/ Accepted: 27 April 2010/Published online: 15 May 2010

(C) Springer-Verlag and AWI 2010

\begin{abstract}
Cycliophora is a recently described phylum to which only two species have been assigned so far, Symbion pandora and $S$. americanus. The cycliophoran life cycle is complex and alternates between asexual and sexual stages. Although not recognized as an entirely independent freeswimming stage when the phylum was first described, the dwarf male has a remarkably complex bodyplan albeit its very small size (approx. 30-40 $\mu \mathrm{m}$ in length). Aiming to increase the knowledge on the gross morphology of the cycliophoran dwarf male, specimens from $S$. pandora and $S$. americanus were analyzed by scanning electron microscopy. In both species, anterior and ventral ciliated fields, as well as paired lateral sensorial organs, were identified, thus confirming previous observations. However, new details are described herein such as the penial
\end{abstract}

Communicated by H.-D. Franke.

R. C. Neves $(\varangle) \cdot$ M. R. da Cunha

Centro de Estudos do Ambiente e do Mar,

Departamento de Biologia, Universidade de Aveiro,

Campus Universitário de Santiago,

3810-193 Aveiro, Portugal

e-mail: ricardon.6@gmail.com

R. C. Neves - R. M. Kristensen

Zoological Museum, Natural History Museum of Denmark,

University of Copenhagen, Universitetsparken 15,

2100 Copenhagen $\varnothing$, Denmark

A. Wanninger

Research Group for Comparative Zoology,

Department of Biology, University of Copenhagen,

Universitetsparken 15, 2100 Copenhagen Ø, Denmark

P. Funch

Ecology and Genetics, Department of Biological Sciences,

Aarhus University, Aarhus, Denmark pouch that encloses the penis. We compare our findings on both Symbion species with the data currently available on other metazoan dwarf males.

Keywords Sexual reproduction - Life cycle . Scanning electron microscopy $\cdot$ Spiralia $\cdot$ Lophotrochozoa Cycliophora

\section{Introduction}

Cycliophora is a metazoan phylum recently erected to accommodate minute marine invertebrates that live commensally on clawed lobsters. So far, only two species have been described, Symbion pandora Funch and Kristensen, 1995 and Symbion americanus Obst, Funch \& Kristensen, 2006, which live on the mouthparts of the Norwegian lobster Nephrops norvegicus Linnaeus, 1758, and the American lobster, Homarus americanus H. Milne-Edwards, 1837, respectively. However, cryptic speciation has been suggested for S. americanus by recent molecular studies (Obst et al. 2005; Baker and Giribet 2007; Baker et al. 2007).

Cycliophorans are characterized by a very complex life cycle that alternates between a sexual and an asexual phase, involving various stages. The most prominent stage is the sessile feeding stage, which lives attached to the setae of the host lobster and filters small food particles from the water (Funch et al. 2008). This stage generates several other life cycle stages by internal budding (Funch and Kristensen 1995, 1997; Kristensen 2002). Feeding individuals are capable of producing Pandora larvae, Prometheus larvae, or females, one at a time, inside a brood chamber. These stages are later released to commence a free-swimming lifestyle. In the asexual phase of the life cycle, the Pandora larva settles close to the maternal 
feeding stage and develops asexually into a new feeding stage. In the sexual phase of the life cycle, a free male stage, the Prometheus larva, settles on the trunk of a feeding stage, probably the maternal individual. The Prometheus larva then produces 1-3 dwarf males inside its body. The dwarf male is regarded as a free stage and is morphologically characterized by a heavy ciliated body and a ventro-posterior penis, among other features (Obst and Funch 2003). The fertilized female is thought to settle on the mouthparts of the same host where it encysts (Funch 1996). A dispersal stage, the chordoid larva, hatches from this cyst, settles on a new host individual, and develops into a new feeding stage.

The phylogenetic position of Cycliophora has been unclear ever since its original description, in which a relationship to Entoprocta and Ectoprocta was hypothesized (cf. Funch and Kristensen 1995). More recently, several studies have suggested a close relationship to either Entoprocta (e.g., Zrzavý et al. 1998; Sørensen et al. 2000; Obst 2003; Funch et al. 2005; Passamanek and Halanych 2006; Paps et al. 2009; Hejnol et al. 2009) or gnathiferan taxa such as Rotifera (e.g., Winnepenninckx et al. 1998; Giribet et al. 2000, 2004; Peterson and Eernisse 2001; Glenner et al. 2004). Because of the incongruent data from gene sequence analyses, further details on the morphology of all life cycle stages are needed for a better understanding of the cycliophoran phylogenetic interrelationships.

The cycliophoran dwarf male has already been described using light and transmission electron microscopy, and at the cytochemical level using confocal laser scanning microscopy (Funch and Kristensen 1997; Obst and Funch 2003; Neves et al. 2009a, b, 2010). However, only one male of Symbion pandora has so far been described by scanning electron microscopy, and its external morphology was apparently altered during the freeze-drying technique used to prepare specimens (cf. Obst and Funch 2003). Also, the high loss of specimens during preparation, due to the minute size of the males, limited the success of this approach. In the study presented herein, we compare the external morphology of the dwarf males of $S$. pandora and S. americanus.

\section{Materials and methods}

Feeding stages with attached Prometheus larvae of the cycliophoran species Symbion pandora were obtained from mouthparts of Norway lobsters, Nephrops norvegicus, collected off the coast of Sagres, Portugal (January 23rd, 2008 ) by local fishermen. Cycliophorans of the species $S$. americanus were obtained from mouthparts of the American lobster, Hommarus americanus, collected from Maine (USA; between October 1st and 15th, 2006). After fixation for $1 \mathrm{~h}$ in $4 \%$ paraformaldehyde (PFA) in $0.1 \mathrm{M}$ phosphate buffer (PBS), specimens were washed $3 \times 15 \mathrm{~min}$ in $0.1 \mathrm{M}$ PBS containing $0.1 \%$ sodium azide and stored at $4^{\circ} \mathrm{C}$.

Paraformaldehyde-fixed males of Symbion americanus were dissected out of attached Prometheus larvae, washed in distilled water and concentrated on a Millipore filter $(12 \mathrm{~mm}$ pore size) using a Swinnex filter (Millipore, Massachusetts, USA) holder to minimize the loss of specimens. The specimens were then post-fixed in $1 \% \mathrm{OsO}_{4}$ for $1 \mathrm{~h}$ at room temperature and subsequently washed with distilled water. Afterward, specimens were dehydrated in an ethanol and an acetone series and critical point dried (CPD) using carbon dioxide. Finally, the membrane with the attached animals was mounted on an aluminum stub with sticky carbon pads and sputter-coated with platinum/palladium alloy. Alternatively, dwarf males of $S$. americanus and S. pandora were attached to circular coverslides coated with poly-L-lysine (solution $0.01 \%$, molecular weight 150,000-300,000; Sigma-Aldrich, Brøndby, Denmark). After post-fixation with $\mathrm{OsO}_{4}$ as described above, the specimens were dehydrated in an ethanol series and immersed in hexamethyldisilazane (HMDS) (Sigma-Aldrich, Brøndby, Denmark) for about $12 \mathrm{~h}$ in a desiccator. Finally, the coverslides with the dwarf males were allowed to dry inside the desiccator for approx. 15 min, mounted on an aluminum stub, and sputtercoated as described above. All specimens were analyzed and digitally photographed using a JEOL JSM-6335F field emission scanning electron microscope (Tokyo, Japan).

\section{Results and discussion}

The external morphology of 10 specimens of Symbion pandora and 16 specimens of $S$. americanus investigated herein showed the typical features that characterize the cycliophoran dwarf male (Figs. 1,2), including the anterior and ventral ciliated fields, the paired lateral sensory organ, and the ventro-posterior penis (see Obst and Funch 2003; Obst et al. 2006). The penis is located inside a pouch-like structure, which is laterally constricted and forms an elongated slit at the cuticle level (Figs. 1a, b, 2a, b). Only the tip of the penis is protruding from the penial pouch. The body region at the base of the penis, in the posterior-most end of the slit, is the only difference between males from the two cycliophoran species. In S. pandora, the cuticle at the base of the penis shows some ridges (Fig. 1b), whereas the same structure is smooth in S. americanus (Fig. 2b). This fact was observed for all specimens investigated and is consistent even for the different drying processes used in this study. Although different drying procedures were applied, no other gross morphological differences were found in the two species investigated. 

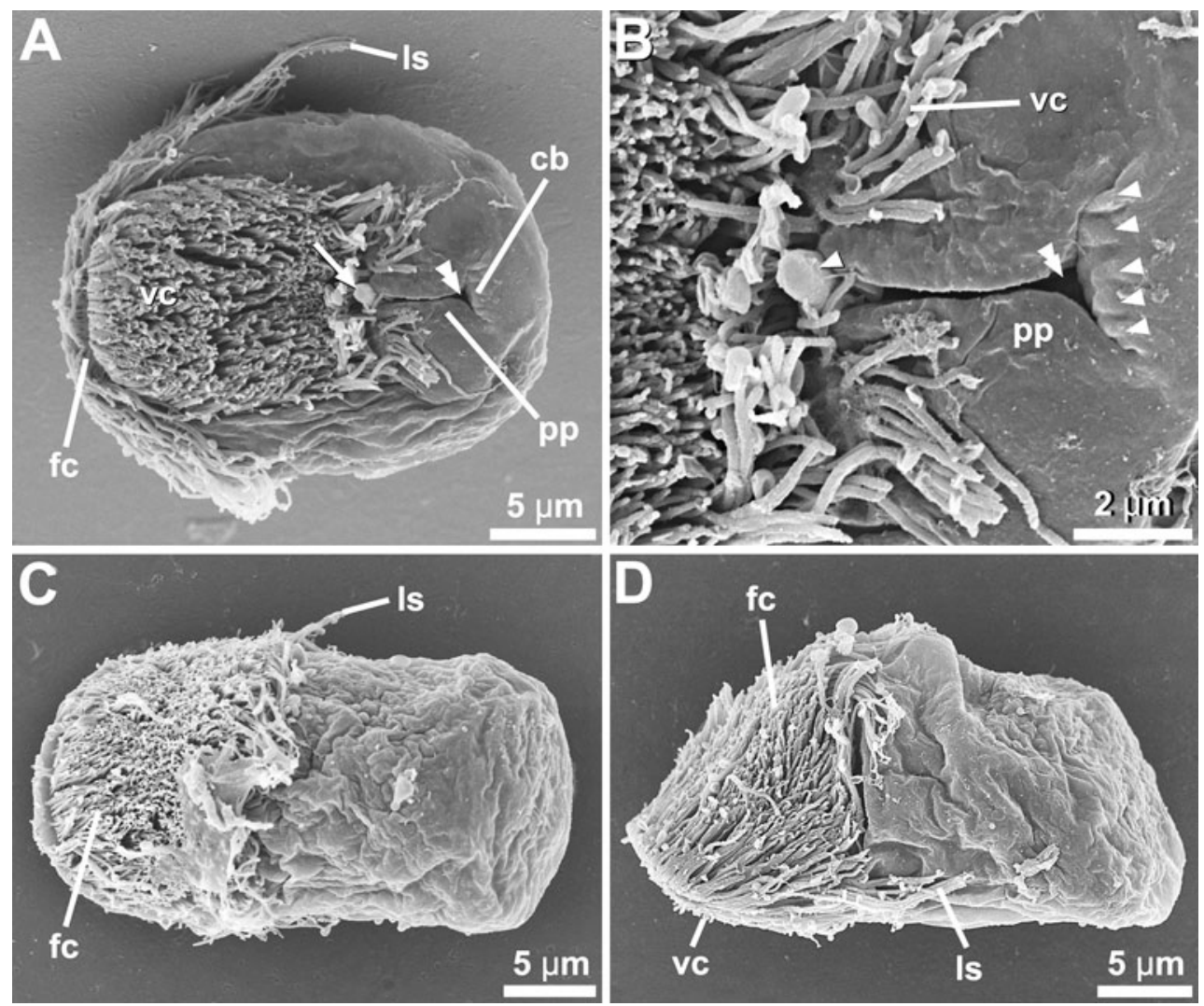

Fig. 1 Symbion pandora, dwarf male. Anterior faces to the left in all aspects. a Ventral view. The tip of the penis (arrow) is extruded while the base is hidden inside the lumen (double arrowhead) of the penial pouch $(p p)$. The lateral sensoria $(l s)$ are composed of long cilia. b Close-up of the penial pouch of the specimen shown in a. Note the

In both cycliophoran species, a ventral ciliated field starts at the very anterior end of the body of the dwarf male and extends posteriorly until the beginning of the penial pouch (Figs. 1a, 2a). No clearly distinguishable longitudinal rows of cilia are found in the somewhat horseshoe-shaped ventral ciliated field. An additional distinct ciliated field likewise emerges in anterior position. This is a frontal ciliated field that spans dorsally through the most anterior third of the male body (Figs. 1c, d, 2c, d) and is clearly separated from the ventral ciliated field by a depression. Sensory cilia located laterally as an extension from the frontal ciliated field are found to be very long $(10-15 \mu \mathrm{m})$ in $S$. pandora and S. americanus (Figs. 1a, c, d, 2a, c, d) (Obst and Funch 2003). The non-ciliated parts of the male integument do not exhibit the typical polygonal sculpture observed in other cycliophoran life cycle stages (e.g., the feeding stage). Different shapes of the body of the dwarf male were found for both species. Some specimens have a roundish, oval body (Figs. 1a, 2a), whereas other specimens present a more elongated, rectangular shape (Figs. 1c, 2c).

Our results corroborate the view of the dwarf male as a totally independent stage in the life cycle of both hitherto

ridges (arrowheads) of the cuticle in the region at the base of the penis $(c b)$. c Dorsal view. d Lateral view. The frontal ciliated field $(f c)$ extends dorsally, covering the anterior-most third of the male body, and a ventral ciliated field $(v c)$ spans from the most anterior body region until the penial pouch

described cycliophoran species. The external phenotype of dwarf males of the two species, Symbion pandora and S. americanus, is very similar. The main difference noticed is related to the cuticle at the base of the penis, which shows some ridges in S. pandora but not in S. americanus. Interestingly, the presence of those ridges in $S$. pandora is confirmed by transmission electron microscopy (cf. Obst and Funch 2003). However, there are no data available on the ultrastructure of males of the species $S$. americanus, which makes further comparisons between both species impossible. Since the ridges were neither observed in HMDS- nor in CPD-dried specimens of S. americanus, this finding is apparently not caused by the different drying processes used for each species.

Earlier descriptions of the dwarf male of Symbion pandora and S. americanus revealed details of sensory elements other than the lateral sensory cilia (Obst and Funch 2003; Obst et al. 2006). In S. pandora, a frontal sensorial organ was identified by TEM but not by SEM, and several palps and a tactile papilla (Fig. 3) were described only for one specimen using SEM. Frontal palps were also described for S. americanus (Obst et al. 2006). These sensorial 



Fig. 2 Symbion americanus, free male. Anterior faces to the left in all aspects. a Ventral view. The penis (arrow) lies inside the lumen (double arrowhead) of the penial pouch ( $p p$ ). Long cilia compose the lateral sensoria $(l s)$. b Close-up of the penial pouch of a specimen in ventral view. Note that the cuticle at the base of the penis $(c b)$ is

devoid of ridges. c Dorsal view. d Ventrolateral view. The frontal ciliated field $(f c)$ covers the dorsal side in the anterior-most third of the male body. On the ventral side, a ciliated field $(v c)$ spans from the anterior-most part of the body until the penial pouch

Fig. 3 Line drawing of the cycliophoran dwarf male (reprinted with permission from Neves et al. 2009b). Lateral view, anterior faces to the left. Scale bar represents $10 \mu \mathrm{m} . \mathrm{cg}$, cerebral glands; $d m$, dorsal muscle; $d p$, dorsal papilla; $d v m$, dorsoventral muscles; $f c$, frontal ciliated field; $f p$, frontal palp; $f s$, frontal sensoria; $g a$, cerebral ganglion; $\mathrm{hm}$, horseshoe-shaped muscles; $l s$, lateral sensoria; $m g$, medial glands; $p e$, penial structure; $p g$, prostate glands; psm, posterior short muscles; $p p$, penial pouch; $s p$, sperm cells; $t e$, testis; $v c$, ventral ciliated field; $v l m$, ventrolateral muscles

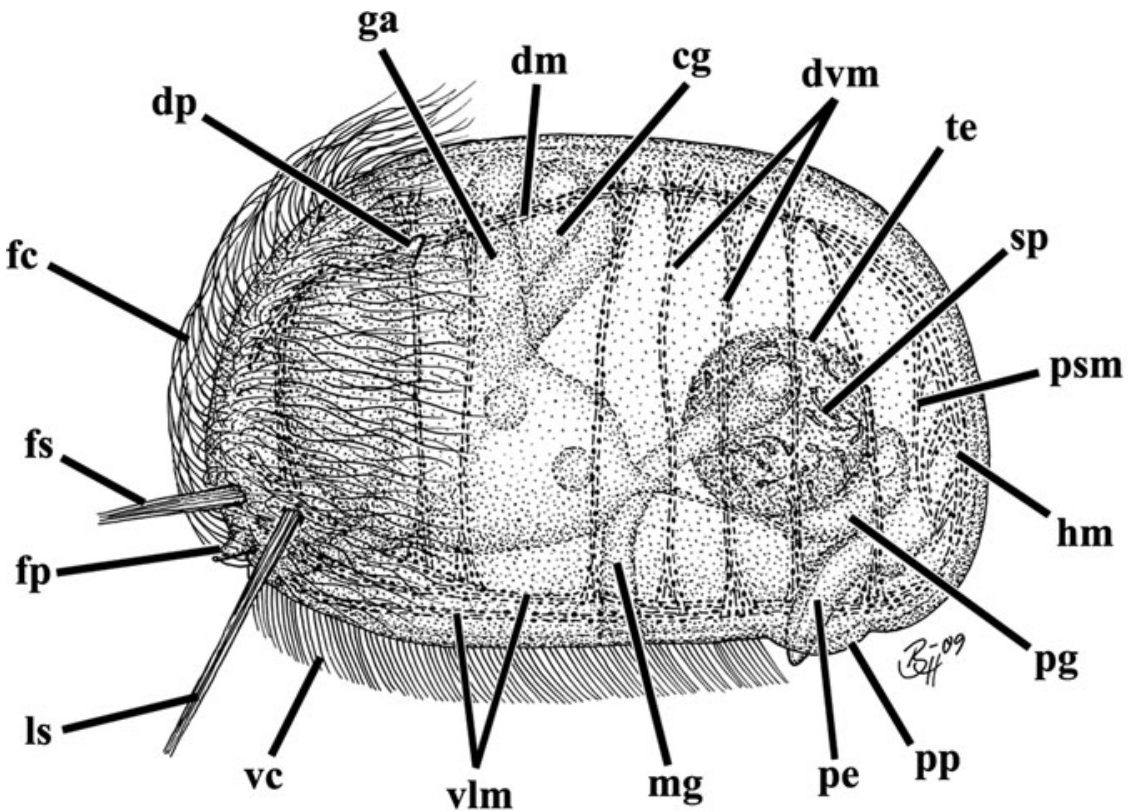


structures could not be identified in any of the males of $S$. pandora or $S$. americanus in our study. However, our results do not argue against the existence of such structures since the frontal ciliated field is very dense and the structures mentioned are possibly covered by cilia.

The various shapes found for the male body were already observed in previous studies by light microscopy (R. C. Neves personal observation). Since the external morphology is not distinct among males with different shapes, all specimens should be fully formed, i.e., at the same developmental phase. Thus, the differences found in the shape of the male body are not indicative of any physiological constraints. It is possible that those differences are related to the number of males developed at the same time and the exact position they adopt inside the attached Prometheus larva.

\section{External morphology and functional implications}

In the original description of Cycliophora, the extremely reduced dwarf male had not been recognized as a free-swimming, independent stage. Instead, an intermediate stage, now termed the Prometheus larva, was originally proposed as the free mature male (cf. Funch and Kristensen 1995, 1997). The cycliophoran dwarf male is now known to have a sophisticated bodyplan that includes a highly complex musculature, a relatively large brain, a pair of ventral longitudinal nerve cords, fully developed gonads and mating structures, sensory organs, and various types of glands (Fig. 3). Accordingly, the details on the external morphology as presented herein strengthen the view of the cycliophoran dwarf male as a free-swimming stage with an important role during sexual reproduction.

So far, fertilization in cycliophorans has never been observed and questions such as when, where, and how this process occurs remain unanswered. The presence of extensive locomotory ciliated fields in the male together with the elongated sensory cilia and an elaborated muscle architecture is indicative of its swimming and crawling capabilities (Fig. 3). Therefore, these locomotory and sensory structures might be necessary for the male to carry out its role in the reproductive process, i.e., find the female and copulate (Funch and Kristensen 1999; Obst and Funch 2003). It is possible that the transfer of sperm cells takes place during the encounter of the male with the female as free-swimming stages. The mechanisms involved in the transfer of the sperm cells to the oocytes, however, remain unknown.

The penis of the dwarf male of both species is a cuticular hollow tube without any aperture at the very distal end (Fig. 3; see also Obst and Funch 2003). The intriguing question is how the sperm cells exit the male body through the penial structure. The fact that the tip of the penis is less than one-third of the diameter of the sperm cells raises the possibility that this organ serves as an anchoring device that facilitates copulation rather than being a true copulatory organ (Obst and Funch 2003). The anchoring cirrus organ could then be used by the male to momentarily pierce the female and somehow liberate the sperm cells from the inside of its body. Both hypotheses are supported by the fact that a complex set of muscles are present in the posterior body region in connection with the base of the penial (or anchoring?) structure (Funch and Kristensen 1997; Obst and Funch 2003; Neves et al. 2009b).

The penial pouch in which the penis lies is a newly described feature for the cycliophoran dwarf male. This structure may be very important during the release of sperm cells by the cycliophoran dwarf male. If, however, the penis would be shown to be an anchoring organ, the penial pouch may act as a receptaculum where the sperm cells accumulate before being transferred to the female's body. This assumption is obviously speculative but based on the aforementioned morphological details of the penial structure.

The cycliophoran male compared to other metazoan dwarf males

Dwarf males are known from several metazoan lineages such as echiurans, polychaetes, siboglinids, monogonont rotifers, barnacles, and spiders (Windoffer and Westheide 1988; Ricci and Melone 1998; Rouse et al. 2004, for reviews see Gilbert and Williamson 1983; Vollrath 1998). Frequently in textbooks (e.g., Ruppert et al. 2004), dwarf males are described as rudimentary sexual intervening forms that are only equipped with the strictly necessary structures to seek a female and copulate. The cycliophoran dwarf male, however, has a very complex body architecture (cf. Funch and Kristensen 1997; Obst and Funch 2003; Neves et al. 2009b). The location of the penis inside a pouch is to our knowledge a new feature among metazoan dwarf males. In some cases, the penial structure is found inside the body (e.g., in polychaetes or monogonont rotifers; see Windoffer and Westheide 1988; Clément and Wurdak 1991) or may be entirely absent (e.g., in echiurans or the siboglinid Osedax; Schuchert and Rieger 1990; Rouse et al. 2004; Worsaae and Rouse 2010). Therefore, more data are necessary to clarify the male-female interaction and the true function of the penial structure and the penial pouch.

In the future, males of both Symbion species should be compared at the ultrastructural level. A better understanding of, e.g., spermatogenesis and sperm morphology will permit further comparisons with other lophotrochozoan taxa, which could result in further insights into the phylogenetic placement and evolution of Cycliophora. 
Acknowledgments We are indebted to Lisbeth Haukrogh (Copenhagen) for technical assistance. RCN greatly appreciates the generous support from the staff of the Department of Biology at the University of Aveiro, the Invertebrate Department at the Zoological Museum (Copenhagen), and the Research Group for Comparative Zoology at the University of Copenhagen. RMK and RCN also thank the NSF Assembling the Tree of Life Protostomes team, especially Greg Rouse, Greg Edgecombe, Gonzalo Giribet, and Andreas Hejnol for many discussions. Research in the laboratory of AW is funded by the EU network MOLMORPH (contract grant number MEST-CT-2005020542) under the 6th framework. RMK is supported by the Danish Research Council (FNU-272-08-056). RCN is supported by the Fundação para a Ciência e a Tecnologia, Portugal (grant number SFRH/BD/24436/2005).

\section{References}

Baker JM, Giribet G (2007) A molecular phylogenetic approach to the phylum Cycliophora provides further evidence for cryptic speciation in Symbion americanus. Zool Scr 36:353-359

Baker JM, Funch P, Giribet G (2007) Cryptic speciation in the recently discovered American cycliophoran Symbion americanus; genetic structure and population expansion. Mar Biol 151:2183-2193

Clément P, Wurdak E (1991) Rotifera. In: Harrison FW, Woollacott RM (eds) Microscopic anatomy of invertebrates, vol 4, Aschelminthes. Wiley-Liss, New York, pp 219-297

Funch P (1996) The chordoid larva of Symbion pandora (Cycliophora) is a modified trochophore. J Morphol 230:231-263

Funch P, Kristensen RM (1995) Cycliophora is a new phylum with affinities to Entoprocta and Ectoprocta. Nature 378:711-714

Funch P, Kristensen RM (1997) Cycliophora. In: Harrison FW, Woollacott RM (eds) Microscopic anatomy of invertebrates, vol 13, Lophophorates, Entoprocta and Cycliophora. Wiley-Liss, New York, pp 409-474

Funch P, Kristensen RM (1999) Cycliophora. In: Knobil E, Neil JD (eds) Encyclopaedia of reproduction, vol 1. Academic Press, New York, pp 800-808

Funch P, Sørensen MV, Obst M (2005) On the phylogenetic position of Rotifera-have we come any further? Hydrobiologia 546:11-28

Funch P, Thor P, Obst M (2008) Symbiotic relations and feeding biology of Symbion pandora (Cycliophora) and Triticella flava (Bryozoa). Vie Milieu 58:185-188

Gilbert JJ, Williamson CE (1983) Sexual dimorphism in zooplankton (Copepoda, Cladocera, and Rotifera). Annu Rev Ecol Syst 14:1-33

Giribet G, Distel DL, Polz M, Sterrer W, Wheeler WC (2000) Triploblastic relationships with emphasis on the acoelomates and the position of Gnathostomulida, Cycliophora, Plathelminthes, and Chaetognatha: a combined approach of $18 \mathrm{~S}$ rDNA sequences and morphology. Syst Biol 49:539-562

Giribet G, Sørensen MV, Funch P, Kristensen RM, Sterrer W (2004) Investigations into the phylogenetic position of Micrognathozoa using four molecular loci. Cladistics 20:1-13

Glenner H, Hansen AJ, Sørensen MV, Ronquist F, Huelsenbeck JP, Willerslev E (2004) Bayesian inference of the metazoan phylogeny: a combined molecular and morphological approach. Curr Biol 14:1644-1649

Hejnol A, Obst M, Stamatakis A, Ott M, Rouse GW, Edgecombe GD, Martinez P, Baguñà J, Bailly X, Jondelius U, Wiens M, Müller
WEG, Seaver E, Wheeler WC, Martindale MQ, Giribet G, Dunn CW (2009) Assessing the root of bilaterian animals with scalable phylogenomic methods. Proc R Soc B 276:4261-4270

Kristensen R (2002) An introduction to Loricifera, Cycliophora, and Micrognathozoa. Integr Comp Biol 42:641-651

Neves RC, Kristensen RM, Wanninger A (2009a) Three-dimensional reconstruction of the musculature of various life cycle stages of the cycliophoran Symbion americanus. J Morphol 270:257-270

Neves RC, Sørensen KJK, Kristensen RM, Wanninger A (2009b) Cycliophoran dwarf males break the rule: high complexity with low cell-numbers. Biol Bull 217:2-5

Neves RC, Cunha MR, Kristensen RM, Wanninger A (2010) Comparative myoanatomy of cycliophoran life cycle stages. J Morphol 271:596-611

Obst M (2003) Cycliophoran relationships revisited. Cladistics 19:159-160

Obst M, Funch P (2003) Dwarf male of Symbion pandora (Cycliophora). J Morphol 255:261-278

Obst M, Funch P, Giribet G (2005) Hidden diversity and host specificity in cycliophorans: a phylogeographic analysis along the North Atlantic and Mediterranean Sea. Mol Ecol 14:44274440

Obst M, Funch P, Kristensen RM (2006) A new species of Cycliophora from the mouthparts of the American lobster, Homarus americanus (Nephropidae, Decapoda). Org Divers Evol 6:83-97

Paps J, Baguñà J, Riutort M (2009) Lophotrochozoa internal phylogeny: new insights from an up-to-date analysis of nuclear ribosomal genes. Proc R Soc B 276:1245-1254

Passamanek Y, Halanych KM (2006) Lophotrochozoan phylogeny assessed with LSU and SSU data: evidence of lophophorate polyphyly. Mol Phylogenet Evol 40:20-28

Peterson KJ, Eernisse DJ (2001) Animal phylogeny and the ancestry of bilaterians: inferences from morphology and 18S rDNA gene sequences. Evol Dev 3:170-205

Ricci C, Melone G (1998) Dwarf males in monogonont rotifers. Aquat Ecol 32:361-365

Rouse G, Goffredi S, Vrijenhoek RC (2004) Osedax: bone-eating marine worms with dwarf males. Science 305:668-671

Ruppert EE, Fox RS, Barnes RD (2004) Invertebrate zoology: a functional evolutionary approach, 7th edn. Thomson, Brooks/ Cole, New York

Schuchert P, Rieger RM (1990) Ultrastructural observations on the dwarf male of Bonellia viridis (Echiura). Acta Zool (Stockh) 71:5-16

Sørensen MV, Funch P, Willerslev E, Hansen AJ, Olesen J (2000) On the phylogeny of the Metazoa in the light of Cycliophora and Micrognathozoa. Zool Anz 239:297-318

Vollrath F (1998) Dwarf males. Trends Ecol Evol 13:159-163

Windoffer R, Westheide W (1988) The nervous system of the male Dinophilus gyrociliatus (Annelida: Polychaeta). I. Number, types and distribution pattern of sensory cells. Acta Zool (Stockh) 69:55-64

Winnepenninckx B, Backeljau T, Kristensen RM (1998) Relations of the new phylum Cycliophora. Nature 393:636-638

Worsaae K, Rouse GW (2010) The simplicity of males: dwarf males of four species of Osedax (Siboglinidae; Annelida) investigated by Confocal Laser Scanning Microscopy. J Morphol 271:127142

Zrzavý J, Mihulka S, Kepka P, Bezděk A, Tietz D (1998) Phylogeny of the Metazoa based on morphological and 18S ribosomal DNA evidence. Cladistics 14:249-285 